\title{
Characterization of dynamic tensile and shear strength of safety bolts in light collision safety devices of a train
}

\author{
J. S. Kim ${ }^{1}$, H. Huh ${ }^{1} \&$ T. S. Kwon ${ }^{2}$ \\ ${ }^{1}$ School of Mechanical, Aerospace and Systems Engineering, \\ KAIST, Korea \\ ${ }^{2}$ Korea Railroad Research Institute, Korea
}

\begin{abstract}
This paper introduces design strategy to develop safety bolts in light collision safety devices under dynamic tensile and shear loading conditions. The light collision safety device is an energy absorbing one for low speed collision of a train. An energy absorbing scenario in the device has several sequential stages. Tension and shear bolts are the key components which make the sequential energy absorbing scenario operated by a series of failures at the specific collapse load. Exact failure loads of tension and shear bolts at crash conditions were determined in aid of finite element analysis considering the dynamic material properties of component materials. Failure loads of tension and shear bolts designed were verified with experiments using tension and shear type jig sets at quasi-static and dynamic loading conditions. Strain gages were attached to both the parallel section of tension bolts to measure the load response acting on tension bolts and the jig set to measure the load responses acting on shear bolts. The quasi-static and dynamic experiments as well as the numerical analysis explained above predicted the load capacities of tension and shear bolts accurately for the crashworthiness design.
\end{abstract}

Keywords: tension bolt, shear bolt, light collision safety device, crash test, finite element analysis.

\section{Introduction}

The crashworthiness of trains is now a major concern since a crash accident of a train leads to a fatal disaster accompanying loss of human lives and properties 
although the train accident is less frequently reported than car accidents [1]. In order to design a reliable Light Collision Safety Device (LCSD) satisfying the standard for the train crashworthiness to minimize passenger injuries and fatalities, a thorough systematic approach is required based on improved energy management concepts and design involving new structural arrangements of higher absorbing capacity in a controlled manner [2]. LCSD is employed as an energy absorber in low speed collision. Repairing charges can be remarkably decreased while passenger safety is also secured by absorbing most crash energy in LCSD. The energy absorbing mechanism of LCSD [5] is operated sequentially in each energy absorber by corresponding levels of load as shown in Fig. 1. The coupler is the first energy absorber whose load-carrying capacity is $1,000 \mathrm{kN}$ and the second energy absorber is an expansion tube whose driving force is over $1,500 \mathrm{kN}$. The tension bolts are installed between the first and second energy absorber and make the energy absorbing mechanism to be sequential to the levels of load [3]. A single tension bolt sustains the tensile load of $375 \mathrm{kN}$ respectively since four tension bolts are designed to carry the load of $1,500 \mathrm{kN}$. After the energy absorption of the expansion tube, LCSD should be detached from the train when the carrying load is over $2,000 \mathrm{kN}$ after eight shear bolts are broken. A single shear bolt sustains the shear load of $250 \mathrm{kN}$ respectively since eight shear bolts are designed to carry the load of 2,000 kN. The maximum load of the designed tension and shear bolts should be verified in dynamic loading conditions experimentally. The load responses are measured with strain gages attached to the parallel section of the tension bolt and the shear type jig set and calibrated by the reference load cell. Since the safety bolts designed undergo dynamic tensile and shear deformation, the dynamic material properties of the base material, $\mathrm{SCM} 440 \mathrm{H}$, should be provided in order to take account of crashworthiness design of both kinds of safety bolts. This paper demonstrates that the maximum load of tension and shear bolts in the quasi-static test is distinguishably different from that in the dynamic tensile and shear tests.

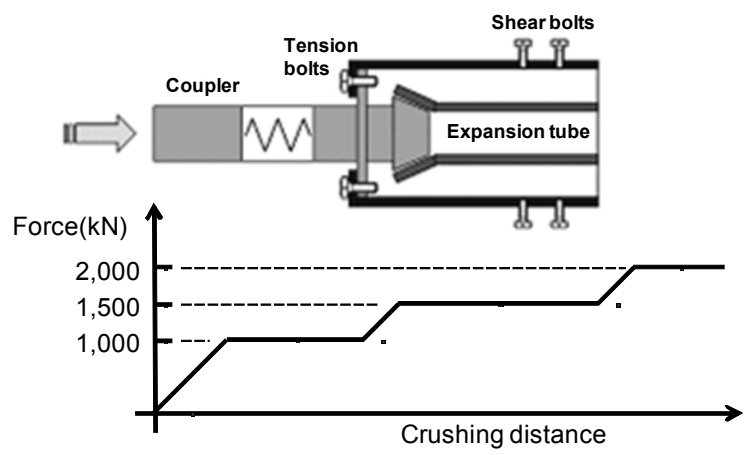

Figure 1: $\quad$ Energy absorbing mechanism of light collision safety devices. 


\section{Design of safety bolts and jig systems}

\subsection{Tension bolts}

The tension bolt designed has the central diameter of $21 \mathrm{~mm}$, the gage length of $30 \mathrm{~mm}$ and the total length of $190 \mathrm{~mm}$ as shown in Fig. 2. The material of tension bolts is $\mathrm{SCM} 440 \mathrm{H}$ after heat treatment. The material is heated up to $850^{\circ} \mathrm{C}$ and held for 3 hours. After the heat treatment, the material is tempered three times at $600^{\circ} \mathrm{C}$ for 5 hours. Stress-strain curves of SCM440H are shown in Fig. 3, which shows lower strain rate sensitivity than that of conventional steels [6-8]. Strain gages are attached on the parallel region which is machined intentionally for load measurement. The load signal is calculated from the strain gage signal by synchronizing with the load signal from a quasi-static universal testing machine. Strain gages are located oppositely to each other in order to compensate a bending effect by constructing a half bridge circuit.

\subsection{Tension type jig system}

The maximum carrying load of the tension bolt designed should be investigated by impact tests since the tension bolt designed undergoes high speed deformation during train crash. For the reason, a High Speed Crash Tester is needed to perform crash tests of the tension bolts as shown in Fig. 4. The maximum speed of the High Speed Crash Tester is $20 \mathrm{~m} / \mathrm{sec}$ and the mass of a carrier is $250 \mathrm{~kg}$. The crash speed is adjusted to $9.5 \mathrm{~m} / \mathrm{sec}(34.2 \mathrm{~km} / \mathrm{h})$ which is almost same as the targeting train speed. A tension type jig system shown in Fig. 5 converts a compressive loading condition to a tensile loading condition since the tension bolts experience tensile loading. The jig system consists of two parts: fixed frame; and movable frame. Fixed frame of the jig system is fixed on the wall by bolting as shown in Fig. 5 and has four main columns which sustain crash loads. The movable frame slides smoothly on the four holes bored in the fixed frame. The tension bolt specimen locates between the fixed frame and the movable frame being fastened by a spanner. Cylindrical buckles are inserted into four columns between two thick plates to sustain pre-tension. Pre-tension of the

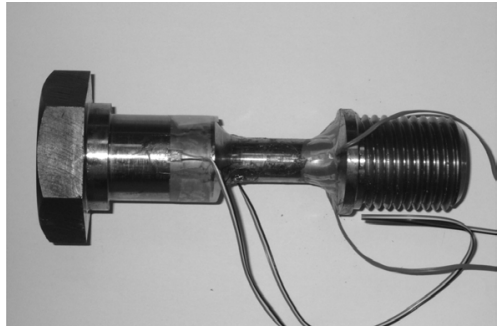

Figure 2: Designed tension bolt.

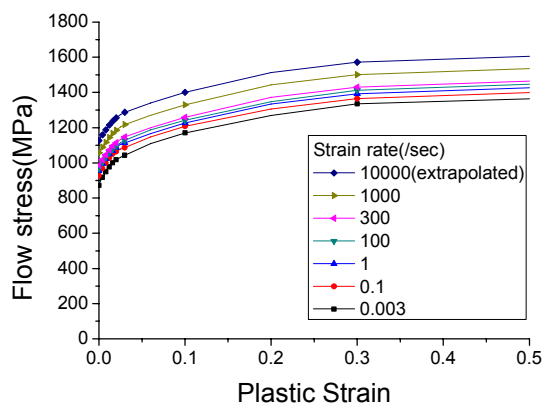

Figure 3: Strain rate dependent stress-strain curves of SCM440H. 


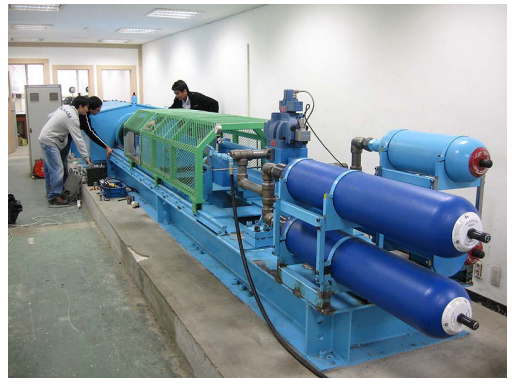

Figure 4: High speed crash tester.
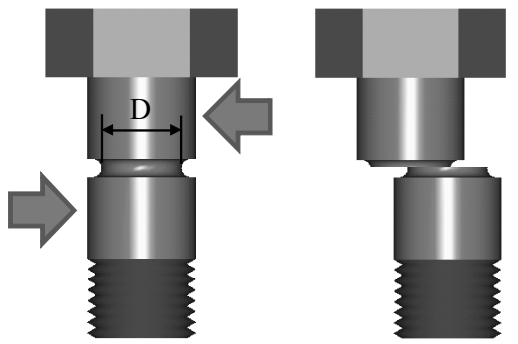

Figure 6: Deformation mechanism of a shear bolt.

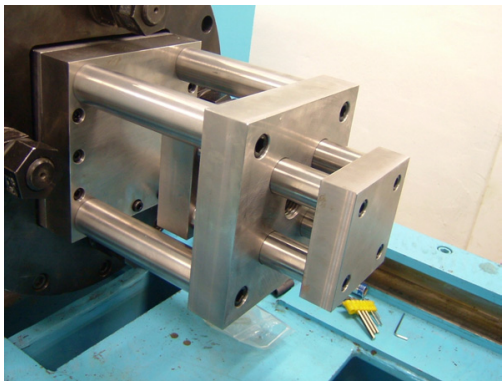

Figure 5: Tension type jig system.

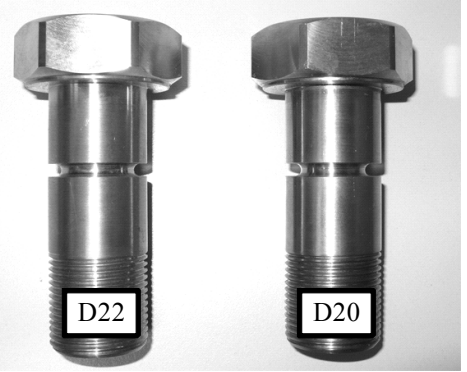

Figure 7: $\quad$ Prepared shear bolts.

tension bolt is continuously monitored by checking the strain signal from a signal conditioning amplifier. After applying designated amount of pre-tension the main controller of the High Speed Crash Tester triggers the carrier with a speed of $9.5 / \mathrm{sec}$. The strain gages attached on the both sides of a specimen measure the load signal accurately. The deformed shapes are continuously taken with 7,000 frames/sec by a high speed camera.

\subsection{Shear bolts}

Basic shapes of shear bolts are commercial standard bolts except they have a narrow groove as shown in Fig. 6. The flat region right below the bolt head is longer than that of conventional bolts since shear bolts need a narrow groove where shear deformation takes place. The basic dimensions of the designed shear bolt are based on the M30 standard bolt. The outer diameter of the shear bolt is $30 \mathrm{~mm}$. Two kinds of shear bolts were prepared by the size of a groove whose diameter, $\mathrm{D}$, is 20 and $22 \mathrm{~mm}$ respectively. The gap of a groove is $4 \mathrm{~mm}$ for all shear bolts. The material for shear bolts is $\mathrm{SCM} 440 \mathrm{H}$ after heat treatment which is same as the material for tension bolts. Stress-strain relations were obtained by high speed material tests up to the strain rate of $1,000 / \mathrm{sec}$ and estimated by modified Johnson-Cook model [4] up to the strain rate of $10,000 / \mathrm{sec}$. The maximum strain rate locates at the center of a groove and is around 3,000/sec at finite element analyses. For the reason, the upper bound of strain rates in piecewise linear data was determined to be 10,000 /sec which can cover the 


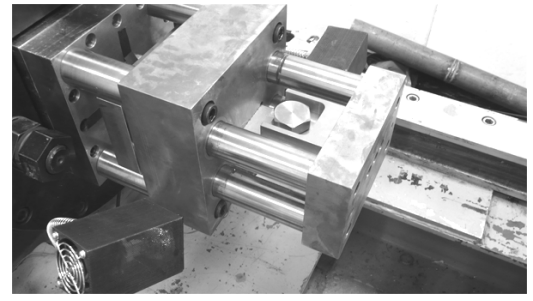

Figure 8: $\quad$ Shear-off jig system.

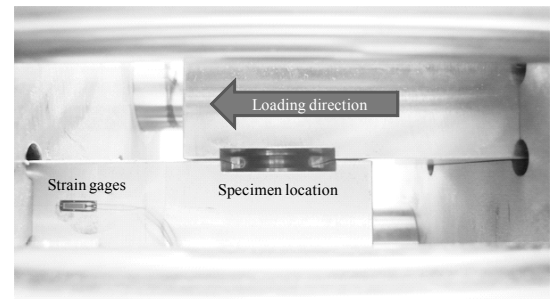

Figure 9: $\quad$ Shear loading mechanism.

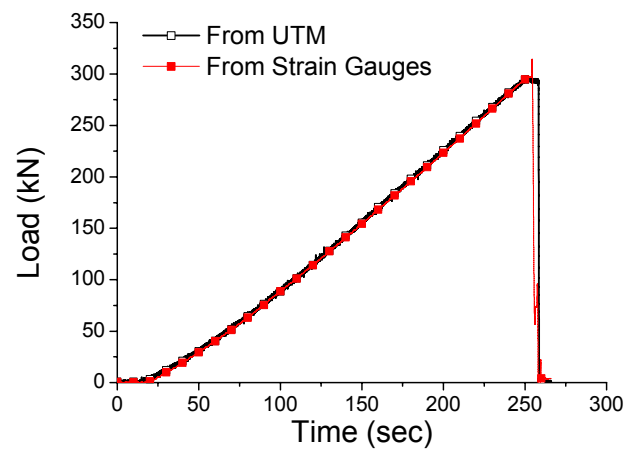

Figure 10: Strain gage output voltage versus load signal from UTM.

maximum strain rate during high speed shear deformation. Shear bolts were prepared by turning as shown in Fig. 7.

\subsection{Shear-off jig system}

The shear bolts are used to install LCSD to the front head of a train. The shear bolt fails when the crush load exceeds the designated load of $250 \mathrm{kN}$. Design of the shear-off jig system is obviously simple for quasi-static shear-off tests, but becomes very complicated for dynamic crash shear-off tests since a crash test needs sufficient loading speed, crash energy and reliable measurement system. Therefore, the shear-off jig system should be carefully designed and verified for a corresponding crash condition. The shear-off jig system in Fig. 8 converts compressive loading to shear loading. A carrier of the crash tester impacts the end of the shear-off jig and the polyurethane pad stops the moving jig after the fracture of the shear bolt. A half bridge circuit of strain gages is devised for a load measurement since the load measurement using load cells sustaining the full jig system has a severe load ringing problem. The strain gages are attached to both sides of a lower jig which is fixed on the left side as shown in Fig. 9. Load calibration of an output signal from strain gages is performed in a quasi-static UTM (Universal Testing Machine) by comparing an output signal from strain gages with the load signal from UTM as shown in Fig. 10. Two signals are in proportion and the scale factor is obtained by dividing the load signal by the 


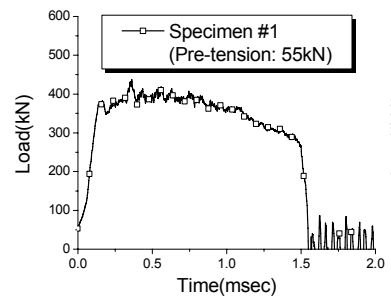

(a)

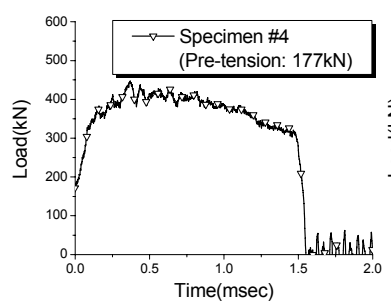

(d)

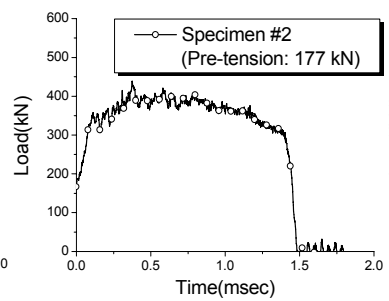

(b)

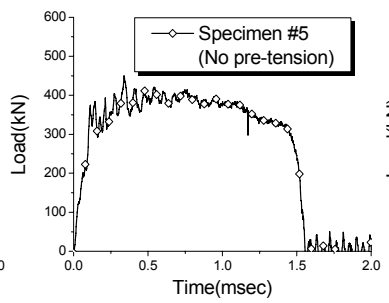

(e)

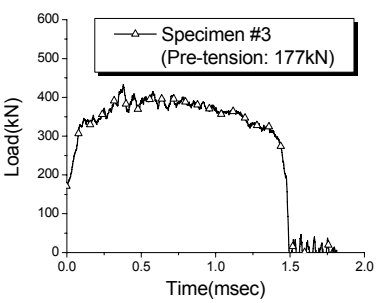

(c)

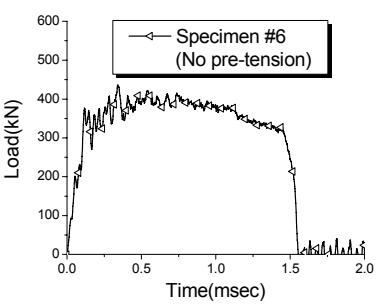

(f)

Figure 11: Load-time curves in the crash tests of tension bolts: (a) specimen \#1(pre-tension: $55 \mathrm{kN}$ ); (b) specimen \#2(pre-tension: $177 \mathrm{kN}$ ); (c) specimen \#3(pre-tension: $177 \mathrm{kN})$; (d) specimen \#4(pretension: $177 \mathrm{kN}$ ); (e) specimen \#5(no pre-tension); (f) specimen \#3(no pre-tension).

output signal from strain gages. The shear-off jig system can perform both quasistatic and dynamic shear-off tests using the same load measurement method.

\section{Experimental and numerical results}

\subsection{Tension bolts}

\subsubsection{Experimental results}

Six testing results are shown in Fig. 11 and Table 1 with respect to an applied pre-tension. Pre-tension denotes tension force applied during fastening tension bolts. The load curve of specimen \#1 starts from $55 \mathrm{kN}$ since the pre-tension is $55 \mathrm{kN}$ in this case. Crash test results of specimens without pre-tension are shown in Fig. 11(e) and (f). The load response shows elastic region, yield point, ultimate tensile strength, necking and fracture finally. The load signal has no load oscillation but a minor noise since the strain gages attached to the tension bolt measure the load acting on the cross section of the tension bolt. Duration of the total deformation of tension bolts is $1.53 \mathrm{msec}$ which is an extremely short time compared to whole energy absorption procedure of LCSD. The load at the yield point of the tension bolt is about $350 \mathrm{kN}$ for all cases and the averaged maximum load is $410.4 \mathrm{kN}$ as shown in Table 1 . The amount of pre-tension has effects on neither maximum loads nor impact durations of the tension bolt. Total displacements of specimens are about $11 \mathrm{~mm}$, that is, total elongation of $33 \%$. Necking occurs at between $0.5 \mathrm{msec}$ and $1.0 \mathrm{msec}$ from sequential deformed 


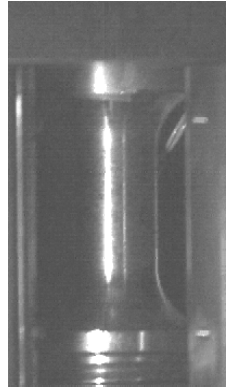

(a)

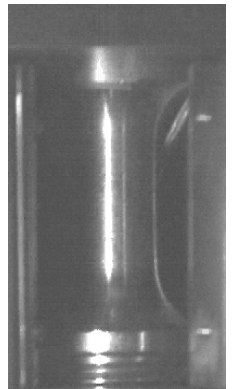

(b)

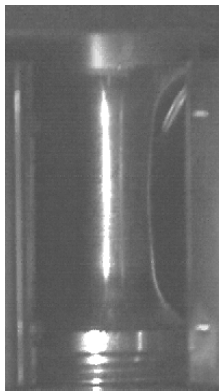

(c)

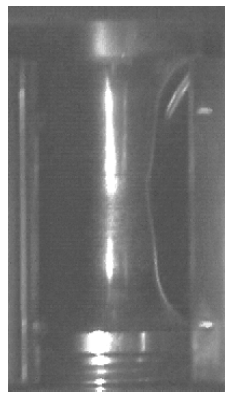

(d)

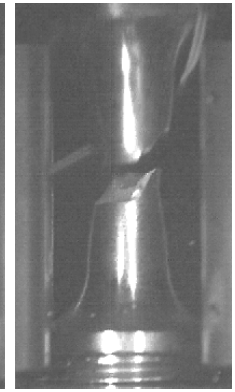

(e)

Figure 12: Deformed shapes during crash test of a tension bolt: (a) $0 \mathrm{msec}$; (b) $0.5 \mathrm{msec}$; (c) $1.0 \mathrm{msec}$; (d) $1.5 \mathrm{msec}$; (e) after fracture.

Table 1: $\quad$ Crash testing results of tension bolts.

\begin{tabular}{|c|c|c|c|}
\hline Specimen number & $\begin{array}{c}\text { Pre-tension } \\
(\mathrm{kN})\end{array}$ & $\begin{array}{c}\text { Maximum load } \\
(\mathrm{kN})\end{array}$ & $\begin{array}{c}\text { Duration } \\
(\mathrm{msec})\end{array}$ \\
\hline 1 & 55 & 413.9 & 1.55 \\
\hline 2 & 177 & 407.9 & 1.49 \\
\hline 3 & 177 & 406.4 & 1.49 \\
\hline 4 & 177 & 427.5 & 1.55 \\
\hline 5 & 0 & 401.2 & 1.55 \\
\hline 6 & 0 & 405.3 & 1.55 \\
\hline \multicolumn{2}{|r|}{ Average } & 410.4 & 1.53 \\
\hline
\end{tabular}

shapes Fig. 12. The maximum load in crash tests is $9.4 \%$ higher than the originally designed maximum load of $250 \mathrm{kN}$ which is in an acceptable range for application to LCSD.

\subsubsection{Numerical results}

Finite element analysis of the tension bolt was performed to verify crash test results. Finite element mesh system has 18,186 nodes and 16,644 brick elements as shown in Fig. 13. Finite element simulation was carried out using LS-DYNA 3D. A piecewise linear model at the different strain rates was adopted in order to consider the strain rate hardening effect as shown in Fig. 3. The right side of the tension bolt was fixed and the bolt head was impacted by a barrier which has a mass of $250 \mathrm{~kg}$ at a speed of $9.5 \mathrm{~m} / \mathrm{sec}$. Fig. 14 shows the load response and energy absorption of both the numerical analysis and the experiment. The load response in the numerical analysis coincides with the experimental result closely. The maximum load at the numerical analysis is $408.5 \mathrm{kN}$ while the averaged maximum load at the experience was $410.4 \mathrm{kN}$. The load curve after the maximum load in the numerical simulation shows slightly higher than that in the experiment. Post necking behavior of the tension bolt is inevitably unstable and stress-strain relations are less reliable than that at the pre-necking region. The 
element is deleted from the calculation when the plastic strain reaches 0.52 . The energy absorption of a single tension bolt is 3,647.2 $\mathrm{J}$ at the experiment and $3,785.3 \mathrm{~J}$ at the numerical simulation which is less than $1 \%$ of absorbing energy for light collision safety devices while most of the crash energy is absorbed in the coupler and the expansion tube. The deformed shapes at each time step during the numerical simulation are shown in Fig. 15. The deformed shapes and contours of the plastic strain explain that necking occurs at the center of a gage region at about $0.5 \mathrm{msec}$ and the fracture occurs at the center due to localized necking. In conclusion, the tension bolts can carry out the role of a mechanical fuse successfully regardless of the amount of pre-tension.
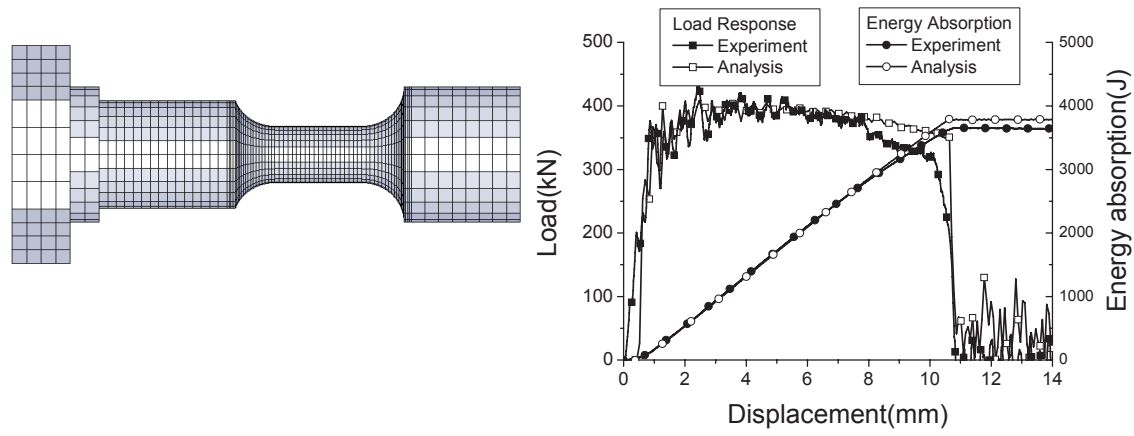

Figure 13: Finite element model Figure 14: Comparison of load of the tension bolt.

responses and energy absorption between experiment and analysis.

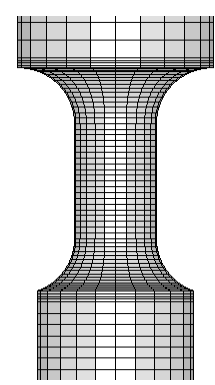

(a)

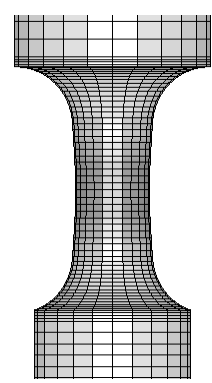

(b)

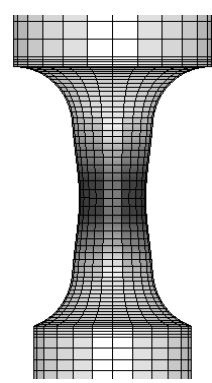

(c)

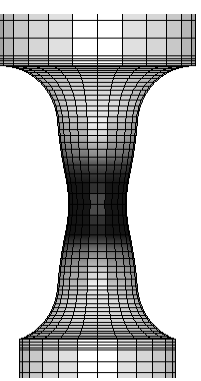

(d)

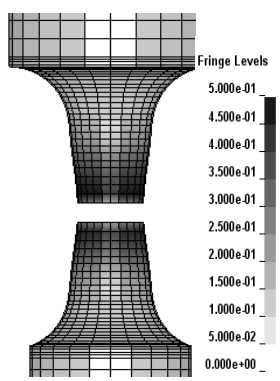

(e)

Figure 15: Deformed shapes of tension bolts in finite element analysis: (a) $0 \mathrm{msec}$; (b) $0.5 \mathrm{msec}$; (c) $1.0 \mathrm{msec}$; (d) $1.5 \mathrm{msec}$; (e) after fracture.

\subsection{Shear bolts}

\subsubsection{Experimental results}

Quasi-static shear tests are performed with a static UTM whose maximum capacity is 50 tonf. The shear-off jig system is installed upon the bed of UTM. A 


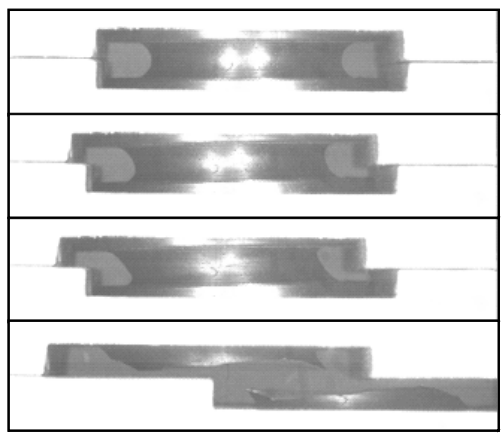

(a)

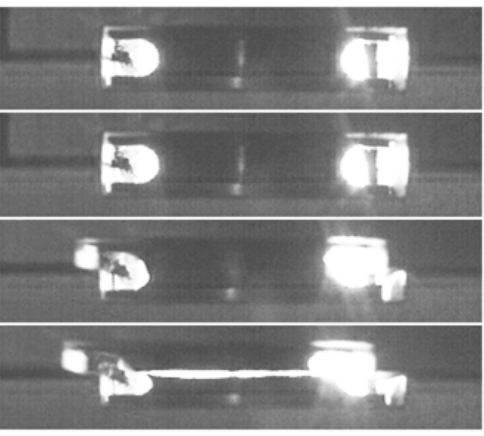

(b)

Figure 16: Deformed shapes during shear deformation: (a) quasi-static shear tests; (b) dynamic shear tests.

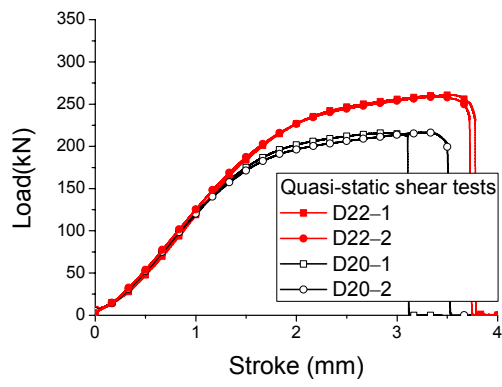

(a)

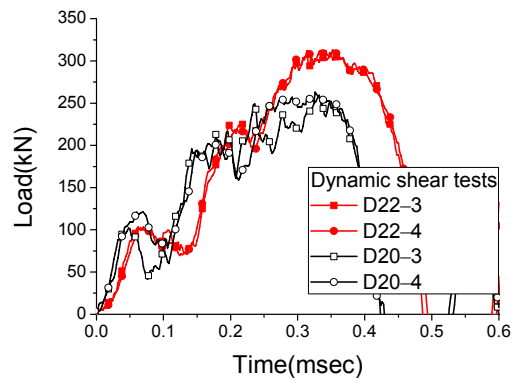

(b)

Figure 17: Load responses of the designed shear bolts: (a) quasi-static shear tests; (b) dynamic shear tests.

data acquisition board on PC captures the signals for the load and displacement from a strain conditioning amplifier and a linear displacement transducer. Sequential deformed shapes during shear deformation are shown in Fig. 16. Deformed shapes show that the specimen is slanted during shear deformation by $7^{\circ}$ which is measured by image processing of the third picture of Fig. 16(a). The load responses during quasi-static and dynamic shear tests are shown in Fig. 17. The maximum loads of shear bolts are $259.6 \mathrm{kN}$ for D22 specimens and 216.1 $\mathrm{kN}$ for D20 specimens. The total stroke until failure is about $3.8 \mathrm{~mm}$ for D22 specimens and $3.5 \mathrm{~mm}$ for D20 specimens. Deformed shapes after quasi-static and dynamic shear tests are shown in Fig. 18. The specimen, D20-1, shows abnormal fracture at quasi-static deformation. The abnormal fracture seems to be affected by initial defects in the original specimen. D22 shear bolts seem to satisfy targeting shear-off load while D20 shear bolts cannot satisfy targeting shear-off load in quasi-static shear tests. Dynamic shear tests are still needed to evaluate the crashworthiness of the shear bolts since the targeting shear load of $250 \mathrm{kN}$, should be evaluated in crash conditions. Dynamic shear tests were performed in the High Speed Crash Tester of a horizontal-type. The shear-off jig system is fixed on the wall horizontally. The mass of a moving carrier is $250 \mathrm{~kg}$ 
Table 2: $\quad$ Maximum shear load in quasi-static and dynamic shear tests.

\begin{tabular}{|c|c|c|c|}
\hline Test method & $\begin{array}{l}\text { Min. diameter } \\
(\mathrm{mm})\end{array}$ & $\begin{array}{c}\text { Specimen } \\
\text { number }\end{array}$ & $\begin{array}{c}\text { Max. shear load } \\
(\mathrm{kN})\end{array}$ \\
\hline \multirow{4}{*}{$\begin{array}{l}\text { Quasi-static } \\
\text { shear tests }\end{array}$} & \multirow{2}{*}{22} & D22-1 & 260.7 \\
\hline & & D22-2 & 258.4 \\
\hline & \multirow{2}{*}{20} & D20-1 & 215.7 \\
\hline & & D20-2 & 216.5 \\
\hline \multirow{4}{*}{$\begin{array}{c}\text { Dynamic shear } \\
\text { tests }\end{array}$} & \multirow{2}{*}{22} & D22-3 & 312.1 \\
\hline & & D22-4 & 313.2 \\
\hline & \multirow{2}{*}{20} & D20-3 & 259.2 \\
\hline & & D20-4 & 262.9 \\
\hline
\end{tabular}

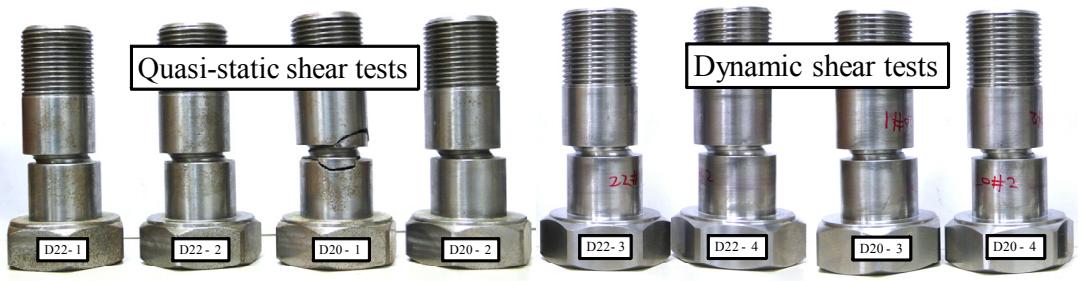

Figure 18: Deformed specimens after quasi-static and crash tests.

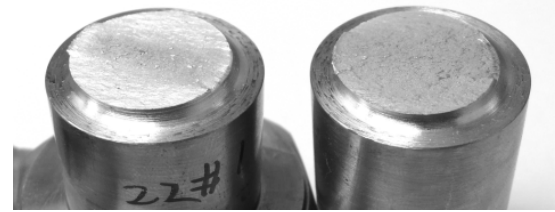

(a)

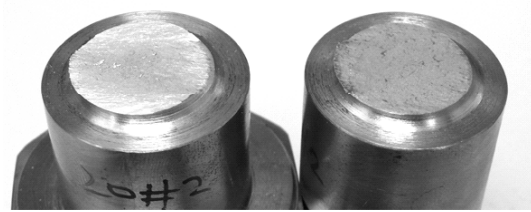

(b)

Figure 19: Typical fracture surface after dynamic shear tests: (a) D22; (b) D20.

and the crash speed is $9.5 \mathrm{~m} / \mathrm{sec}$. The deformed shapes are continuously taken by a high speed camera with 7,000 frames/sec. Load responses are obtained from the strain conditioning amplifier at the sampling rate of $500 \mathrm{kHz}$ as shown in Fig. 17(b). The load responses at dynamic shear tests are highly reliable after $0.2 \mathrm{msec}$ since the load oscillation caused by load ringing phenomena decreases after $0.2 \mathrm{msec}$. The maximum shear-off loads in dynamic shear tests are $312.6 \mathrm{kN}$ for D22 specimens and $261.1 \mathrm{kN}$ for D20 specimens. Both D22 and D20 specimens show clear fracture surfaces after quasi-static and dynamic shear tests as shown in Fig. 19. Duration of dynamic shear tests is ranged from 0.43 to $0.49 \mathrm{msec}$ and the total stroke is ranged from $3.9 \mathrm{~mm}$ to $4.5 \mathrm{~mm}$. Consequently, D20 shear bolts satisfydesign criteria, the maximum shear load and clear fracture surface, at the crash speed of $9.5 \mathrm{~m} / \mathrm{sec}$. 


\subsubsection{Numerical results}

Finite element analysis of the shear bolt was performed to verify crash test results. The material properties used are piecewise linear stress-strain curves shown in Fig. 3. The loading direction is not perfectly aligned, but has an inclined angle of 7 degree for quasi-static shear tests and 2 degree for dynamic shear tests according to image analyses. For the reason, the bottom side of the shear region is fixed and the velocity boundary condition is applied on the top of the shear region with the inclined angle. The effective plastic strain at fracture is 0.52 which is same as that for the tension bolt analysis. Finite element mesh system has 12,032 brick elements as shown in Fig. 21. Sequential deformed shapes are shown in Fig. 22. The elastic region of experimental loaddisplacement curves in Fig. 23 is corrected in accordance with the numerical load-displacement curves. Mechanical arrangement and elastic deformation of shear-off jig system cause disagreement of the elastic region between experiments and FEA. Fig. 23(a) shows FEA results in comparison to quasistatic shear test results. The maximum load from FEA coincides with that from the experiment as well as the fracture point. FEA results for the dynamic shear test are also in coincidence with the experimental results in the maximum load and fracture point. The maximum shear load for the D20 shear bolt is $216.1 \mathrm{kN}$ for the experiment and $218.2 \mathrm{kN}$ for FEA in quasi-static shear tests while the

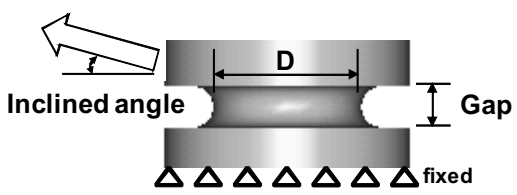

Figure 20: Boundary conditions for shear analysis.

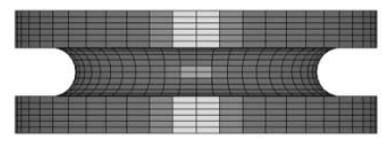

Figure 21: Finite element model of the shear bolt.

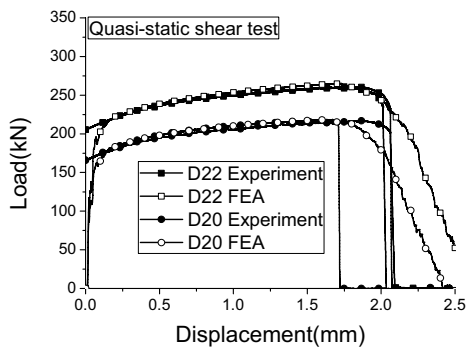

(a)

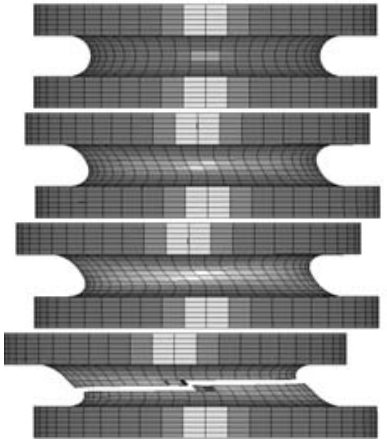

Figure 22: Sequential deformed shapes.

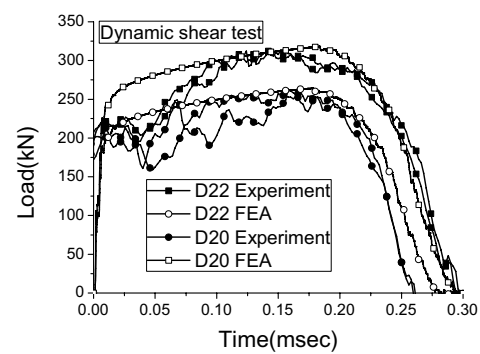

(b)

Figure 23: Load-time curves from experiments and FEA: (a) quasi-static shear tests; (b) dynamic shear tests. 
maximum shear load for the D20 shear bolt is $261.1 \mathrm{kN}$ for the experiment and $264.2 \mathrm{kN}$ for FEA in the dynamic shear test. Numerical simulation with dynamic material properties of SCM440H precisely predicted the experimental result.

\section{Conclusion}

Crash test results of the tension bolt designed showed the maximum load of $410.5 \mathrm{kN}$ and the absorbed energy of $3785.3 \mathrm{~J}$ while the target load was $375 \mathrm{kN}$. The tensile testing devices were designed to perform the crash tests of tension bolts at the High Speed Crash Tester. The load measuring system using strain gages was calibrated in a proper manner and carried out measurement of load responses successfully. It is noted that the amount of applied pre-tension had no effects on the maximum load. The shear bolts for Light Collision Safety Devices were designed and evaluated by quasi-static and dynamic shear tests. The designed shear bolts, D20 specimens, showed the maximum shear load of 216.1 $\mathrm{kN}$ for quasi-static shear tests and $261.1 \mathrm{kN}$ for dynamic shear tests while D22 specimens showed the maximum shear load of $259.6 \mathrm{kN}$ for quasi-static shear tests and $312.6 \mathrm{kN}$ for dynamic shear tests. The maximum shear load of D20 specimens is $261.1 \mathrm{kN}$ which is $4.4 \%$ larger than the targeting shear-off load. Accordingly, D20 shear bolts with a material of SCM440H operate sufficient function in Light Collision Safety Devices. The numerical simulation for the tension and shear bolts with dynamic material properties of SCM440H predicted the experimental results closely.

\section{References}

[1] Safetrain, BRITE/EURAM Project n.BE-3092, Dynamic tests, SAFETRAIN Technical Report T8.2-F, Deutsche Bann, Berlin, Germany, 2001.

[2] Lewis, J. H., Development of Crash Vehicle structures for Railways. Proc. of WCRR '94: Paris, pp. 893-900, 1994.

[3] Kim, J. S., Huh, H., Choi, W. M. \& Kwon, T. S., Crash Tests of Tension Bolts in Light Safety Collision Devices, Key Engineering Materials, 385387, pp. 685-688, 2008.

[4] Huh, H., Kang, W. J., \& Han, S. S., A Tension Split Hopkinson Bar for Investigating the Dynamic Behavior of Sheet Metals. Exp. Mech., 42(1), pp. $8-17,2002$.

[5] Koo, J. -S. \& Youn, Y. H., Crashworthy Design and Evaluation on the Front-End Structure of Korean High Speed Train. Int. J. Automot. Techn., 5(3), pp. 173-180, 2004.

[6] Kim, J. S., Huh, H., Lee, K. W., Ha, D. Y., Yeo, T. J. \& Park, S. J., Evaluation of Dynamic Tensile Characteristics of Polypropylene with Temperature Variation. Int. J. Automot. Techn., 7(5), pp. 571-577, 2006.

[7] Huh, H., Kim, S. B., Song, J. H. \& Lim, J. H., Dynamic tensile characteristics of TRIP-type and DP-type steel sheets for an auto-body. Int. J. Mech. Sci., 50, pp. 918-931, 2008.

[8] Huh, H., Lim, J. H. \& Park, S. H., High speed tensile test of steel sheets for the stress-strain curve at the intermediate strain rate. Int. J. Automot. Techn., 10(2), in print, 2009. 